\title{
Concealment and Disclosure: The Cholera Crisis of 1969-70 in Korea
}

1. Introduction

2. Establishment of a Health Prevention System and Cholera Prevention in 1963

1) Improvement of Health Prevention Regulations and Execution of the "Revolutionary Tasks"

2) Cholera Epidemic and Response, 1963-64

3. Cholera Epidemic of 1969-70 and Politicization of the Anti-Cholera Administration

1) Cholera Epidemic of 1969 and the Anti-Cholera Administration

2) Cholera Controversy and Regression of the Health Administration

4. Conclusion

\section{Introduction}

In the 20th century, Korea has experienced several cholera epidemics in 1919-20, 1946, and the 1960s. In 1919, 16,991 cases and 11,084 deaths occurred, resulting in a mortality of 65.2\% (Korean Government-General, 1920: 13-16). In 1920, 24,229 cases and 13,568 deaths occurred, with a

\footnotetext{
† This research was supported by Daegu University Research Grant, 2020.

* Assistant Professor, Dept. of History Education, Daegu University, Chinese History and East Asian History of Medicine major / E-mail: jerry0406@daegu. ac. kr
} 
mortality of 56.0\% (Korean Government-General, 1921: 17-18). Finally, in 1946 , there were 15,748 patients and 10,191 deaths, recording a $64.7 \%$ mortality rate (Choi, 1949: 34).

In the 1960s, a new type of cholera caused by El Tor Vibrio cholerae was dominant. The El Tor biotype has a lower mortality rate than the Classical Asiatic biotype of Vibrio cholerae does, but it is highly contagious and has an unclear mode of propagation. The 1960s in Korea was the era of the Park Chŏng-hŭi government (1961-79); having taken power via a military coup, one of the first tasks of the Park government was to establish a modern health prevention system to address the problems of widespread infectious diseases. During this period, acute infectious diseases, such as smallpox, typhus fever, polio, and rabies, decreased due to the mass production of vaccines and antibiotics. However, Korean society was still struggling with cholera, typhoid fever, and encephalitis. In the 1960s, cholera, among all these diseases, ravaged Korea as part of the seventh worldwide cholera pandemic, and how to overcome anticipated cholera epidemics became a test for the proper functioning of the national health system (KSID, 2018).

Since 1962, the Korean government had enacted various laws and systems, such as the Health Center Law and the Prevention of Communicable Diseases Act, to build a modern health prevention system. To implement the system successfully, the government needed to integrate and expand research and investigation projects as well as education and training programs. The National Institutes of Health (NIH) under the leadership of the Ministry of Health and Social Affairs supervised the production and inspection of medicines necessary for disease management, and public health centers took care of public health 
and managed infectious diseases.

Cholera is a waterborne communicable disease, and therefore, it is heavily affected by the water supply system; given that a public water supply first became available in Korea in the mid-20th century, it is predictable why cholera epidemics emerged in this period. Cholera is also highly contagious and closely connected to global environments. The 1960s represented an important turning point in which this waterborne epidemic formed a regional and local pattern, different from that of the previous global cholera pandemics. Especially since the 1960s, the El Tor biotype of Vibrio cholerae had become a popular form; the deadly highgrade Classical Asiatic biotype of the previous eras disappeared as its toxicity waned. It was also the El Tor biotype that was prevalent in Korea between 1963 and 1970 (Kim, 1972: 19).

During the 1960s, Korea had endured cholera outbreaks for a total of four years in 1963-64 and 1969-70; in 1969, the worst outbreak occurred, involving 1,538 patients and 137 deaths. This was the second largest incidence of cholera morbidity and mortality after the Liberation of Korea in 1945, and it exposed the problems in the healthcare system that the Park government had adopted in the 1960s. A National Assembly Inspection Report attributed the 1969 cholera epidemic to lack of government funding, deterioration of disinfection equipment, inadequate quarantine facilities, and low public awareness (Committee on Health and Social Affairs in the Korean National Assembly, 1970: 8). Recent studies have pointed out that overall, the 1960s' system failed as it lacked proper government responses, relevant public health systems, and adequate water and wastewater infrastructures (Ch'ŏn and Kim, 2015; Kim, 2015). Furthermore, one of the studies reveals that during the 
cholera disaster of 1969 , cholera control was limited because the Park government could not effectively operate its biopower due to his weak power (Kim, 2015). However, the claim that the 1969 cholera epidemic met a disastrous outcome due to total insolvency of the government and the limitations of the era has obscured the root causes of one of the worst cholera outbreaks in the history of modern Korea. Throughout the 1960s, the Park government's power had never been weak, and it could have achieved better results in cholera prevention.

This paper seeks to pay attention to the reasons why the cholera preventive measures in the 1960s produced different results at different times and the characteristics of the military government's prevention administration during the period. In particular, this paper examines whether the healthcare system established in the early days of the Third Republic of Korea (1963-1972) functioned properly and whether the media and medical professionals, who were supposed to monitor and support the operation of the health prevention system, faithfully fulfilled their role.

Since the outbreak of the epidemic in 1969, the nature of cholera and its path of transmission have been debated by many scholars (Kim, 1991; Lim, 2002). They explain that new infectious strains, an external inflow through global exchanges, and possibly intentional distribution of bacteria shaped the ways in which cholera was transmitted at that time. In order to accurately understand the nature of cholera in 1969, it is necessary to look into the cholera research and prevention activities of Kee Yong-suk (1905-74), who took the lead in cholera prevention on behalf of the Korean medical community. A leading expert on microbes in Korea, Kee participated in dealing with the cholera epidemic of 1969 as a member 
of a government investigation team. He argued that the epidemic was caused by a new microorganism with the characteristics of mixed infections in which both Vibrio parahaemolyticus and Vibrio cholerae were present. Although his argument was different from the findings of the government agencies and caused confusion in government policy, his cholera research had long been accepted as unproblematic (Lee, 2007; Kim, 2014). This paper attempts to restore the voices of medical professionals who opposed Kee's arguments with new information they acquired on cholera. Furthermore, this paper also aims to show that while Park Chŏng-hŭi's military government manipulated cholera statistics for long-term rule, the media did not trust health authorities to report cholera cases accurately and tried to expose the problems that emerged in the "cholera prevention war" by introducing different medical views.

\section{Establishment of a Health Prevention System and Cholera Prevention in 1963}

1) Improvement of Health Prevention Regulations and Execution of the "Revolutionary Tasks"

In the 1960s, the Korean government amended the existing public health laws, including the Medical Law (March 20, 1962), the Health Center Law (September 24, 1962), and the Infectious Disease Prevention Act (February 9, 1963; IDPA); moreover, it enacted new laws, such as the Health Insurance Act (1963), the Parasite Disease Prevention Act (1966), and the Tuberculosis Prevention Act (1967). According to the revised Medical Law, the classification of medical practitioners into Tier 1 (physicians and dentists), Tier 2 (traditional Korean medical doctors), 
and Tier 3 (health officers, midwives, and nurses) was abolished. The revised Medical Law referred to an institution with more than two medical departments, in addition to its own personnel and facilities, as a hospital and one with more than 12 medical departments as a general hospital. In addition, the revised Public Health Center Law changed the purpose of establishing public health centers from "the improvement of public health and the prevention of infectious diseases" to "the rational management of the health administration and the improvement and promotion of public health." It established one public health center in each county, and the center's scopes and activities were extended from the prevention of epidemics and public health initiatives to tasks related to national health.

The IDPA was expanded to control a total of 20 to 22 infectious diseases, including rabies and malaria, which were divided into three groups. "Group 1 infectious diseases" covered 12 diseases-cholera, plague, typhus, rash fever, typhoid, paratyphoid, smallpox, scarlet fever, diphtheria, dysentery, recurrent fever, and epidemic meningitis. "Group 2 infectious diseases" comprised of seven kinds of diseases, namely acute precognitive grayingitis, pertussis, marginal, mumps, epidemic encephalitis, rabies, and malaria. The "Group 3 infectious diseases" were tuberculosis, leprosy, and sexually transmitted diseases. The IDPA required infectious diseases in Groups 1 and 2 to be reported to mayors and county governors immediately after diagnosis, while Group 3 diseases would be reported at least once a month. In addition, the IDPA changed leprosy from Group 1 to Group 3 for patient care and corpses management. The IDPA required workplaces with more than 15 employees to receive tuberculosis checkups and vaccinations at least 
once a year. ${ }^{1)}$ It does not mean that the IDPA came to wield stronger authority at that time; rather, its tasks were readjusted for efficiency under the new military government.

Revising the Medical Law and the IDPA represented the efforts of the military government to reform the healthcare system. In particular, the government introduced a dualized health prevention system, in which local governments were put in charge of regular prevention efforts and the central government took responsibility for emergency preventive measures. However, the new government sanitary regulations only partially modified the existing laws and regulations, and it is hard to say that there was a fundamental change in national sanitary policy at that time. With the development of vaccines and antibiotics, the incidence rates of smallpox, typhus fever, and diphtheria plunged, but cholera, typhoid fever, and encephalitis were still rampant (Ministry of Health and Social Affairs, 1971).

In the early 1960s, cholera was widespread in Asia, and as the Korean government and the media gathered information on the incidence of cholera, health authorities prepared necessary measures against the disease. In 1961 and 62, the focus of the Korean health prevention system was mainly on encephalitis and typhoid. For this purpose, the government designated May to October as the main quarantine period and mobilized military personnel to carry out insect repulsion, immunization, and environmental improvement work. In August 1962, the Ministry of Health and Social Affairs, which obtained information that cholera had been found in various regions of Southeast Asia, organized the "Cholera

1) "Revised Law in the Infectious Disease Prevention Act [Chŏnyŏmbyŏng yebangbŏpjung kaejŏngbŏpryul]”, Kwanbo, 9 February 1963, pp. 572-573. 
Emergency Measures Meeting" and ordered the implementation of strong preventive initiatives (Ministry of Health and Social Affairs, 1962).

First, the Ministry of Health and Social Affairs called it to attention that the project to deal with the cholera epidemic had been part of the "Revolutionary Tasks (Hyŏkmyŏng kwaŏp)" and emphasized the need for strong anti-cholera measures. At the same time, health authorities checked the status of cholera in Southeast Asia, including the Philippines and Taiwan, prepared a manual to cope with cholera outbreaks in neighboring countries, reviewed surveillance networks and reporting systems, and adopted measures to expand vaccines and immunization. The manual summarized various steps for each department to take as well as emergency budgeting. In the case of neighboring countries, five-day procedures including quarantine, disinfection, and inoculation were prescribed. As for Korea, local ministers of each city and province took responsibility for carrying out the preventive measures. An infected person and his/her family were required to receive five days of isolation treatment (Ministry of Health and Social Affairs, 1962).

Because cholera was highly contagious and rapidly transmitted, precise strategies and tactics were needed to prepare for the "cholera prevention war." First of all, a cholera infected area was divided into the following cholera prevention zones for each patient: District A (patient level), District B (Li or Tong; Village), District C (Myŏn; Township), District D (Kun; County), and District E (To; Province) (see figure 1). Thus, a radius of 200 meters around the patient was set as District A, and this was divided into five zones for each administrative unit. Family members and other persons who had been in contact with the patient for five days before the disease was identified were grouped and served 
meals in schools or public offices in District C (Seoul City Public Service Training Center in Hannam-tong, Seoul). District B was designated as the Red Zone, and all traffic to the area was prohibited. Travelers could enter District D, but they could not leave. District E could also require travel certificates as needed.

Figure 1. Cholera prevention zones.

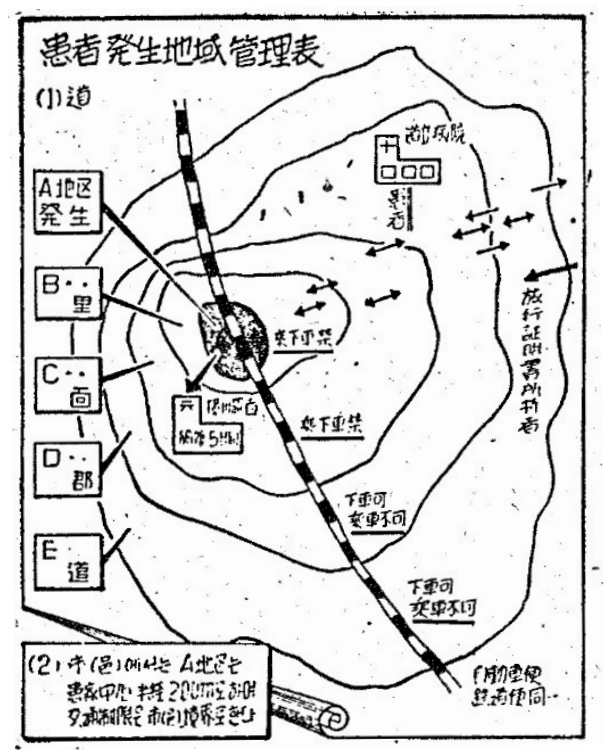

(Ministry of Health and Social Affairs, 1962)

Immunizations needed to be administered to residents in District D, with all its residents over the age of one year to be vaccinated. To enter District D, students had to carry an inoculation certificate. In addition, the police branch in the jurisdiction should contact any person who had left the area five days before the outbreak and monitor him/her for five days. Thus, the "cholera emergency measures" of August 1962 were written in 
a detailed and structured manner (Ministry of Health and Social Affairs, 1962).

\section{2) Cholera Epidemic and Response, 1963-64}

The cholera pandemic of the early 1960s can be traced to 1961 in Sulawesi, Indonesia. In 1961 and 1962, the Korean government prepared a preliminary warning system and an immunization scheme for a possible cholera epidemic, and they were implemented in August 1963. On September 17, 1963, a 49-year-old male resident of Kamch'ŏn-tong, Sŏ-ku, Pusan, suffered from a mysterious illness and died after enduring diarrhea, headache, and paralysis. The number of patients suffering from vomiting, diarrhea, and dehydration increased, but health authorities and doctors in Pusan could not identify the disease. On September 19, a doctor at the Pusan Medical Center Pathology Laboratory, Lee Kŏn-jin, judged it to be Asiatic cholera after checking the bacteria cultured in the stool test of the inpatients at the emergency room. To reassure himself, he reaffirmed the results of the screening with local experts and sent the separated fungi and stool culture to the National Institute of Disease (NID). On September 21, Lee ruled that the disease was cholera of the El Tor Ogawa type. The NID also announced the same result on that day (Ministry of Health and Social Affairs, 1963a: 23). The Pusan Metropolitan authorities set up the cholera control headquarters at the city hall and the treatment headquarters at a university hospital and prohibited foreign ships from entering the area. They also made it mandatory for schools of all levels to be closed and for individuals to get vaccination certificates. ${ }^{2)}$

2) "Memorandum in 1963 [1963nyŏn ŭi pimangrok]," Dong-A Ilbo, 14 December 1963. 
Despite these efforts, after the first case was confirmed in Pusan on September 21, 1963, cholera began to spread in Kyŏngsang province and Kangwŏn province; it then struck Seoul, Kyŏnggi, and Chŏnnam provinces. The cholera control headquarters was established on September 21 immediately after the report of the first cholera patient, and on September 23, a cholera prevention committee was established. Also on September 23, it was reported that Seoul had its first cholera patient. ${ }^{3)}$ In Seoul, the Hygienic Test Laboratory, the National Medical Center (NMC), and the NID assisted in the examination of pathogens. The Pusan University College of Medicine, the Pusan Medical Center, the Pusan Sea Port and its Quarantine Station, and the 5th Army Hospital in Pusan also conducted the examination of pathogens. On September 24, the Ministry of Health and Social Affairs ordered 1,400 students in their third and fourth years of medical school to go to 189 public health centers nationwide, and it assigned military medical centers, medics, and vehicles to these public health centers. In addition, the Ministry of Health and Welfare established inspection and prevention facilities and allotted a budget of 200 million won. By September 28, a week after the first patient's death, the number of cases reached 406; of these, 27 died and 17 recovered (Ministry of Health and Social Affairs, 1963c). On October 18, the last patient was reported. The cholera control headquarters was dismantled on November 1, and the cholera epidemic of 1963 was over. The final number of the patients reported was 414 and the death toll was 36 (8.7\%). (Chŏn, 1965: 4).

Internally, the government mobilized 1,732 people in the cholera

3) "Invasion of Cholera patients in Seoul [Seoul edo cholera hwanja ch'imyip]," Kyunghyang Shinmun, 23 September 1963. 
defense, including 15 inspectors, 1,447 medical students, 200 military surgeons, and 70 specialists. Cholera patients' samples were divided among the NID, the NIH, the NMC, and the Hygienic Test Center of Seoul. The government organized 20 students from health graduate schools to conduct an epidemiological investigation. In addition, the government installed quarantine rooms at each university and provincial hospital to isolate cholera patients and to generate more than 10 times as much vaccine as usual. Foreign countries were asked to assist in vaccination against neighboring countries, and the Korean government requested vaccines from the Red Cross, the Eighth United States Army (EUSA), the United States Agency for International Development (USAID), and the World Health Organization (WHO). In addition, the US Navy would assist Colonel Robert Allan Phillips (1906-76), the chief of the US Navy Medical Research Unit II and cholera specialist, who was working in Taiwan, and three researchers to deliver the cholera treatment to Korea (Ministry of Health and Social Affairs, 1963c). Colonel Phillips claimed that his treatment was extremely effective with a fatality rate of less than $2 \%$ (Chŏn, 1965: 5).

This outbreak marked the first time the El Tor biotype of Vibrio cholerae was identified in Korea. Specific strains of the El Tor biotype, the Ogawa and Inaba serotypes, were detected in Pusan at about the same time. The characteristics of the cholera epidemic in 1963 were as follows: $52.3 \%$ of all patients were younger than 30 years old, and there was little difference between the numbers of male and female patients. In addition, $73.2 \%$ of the patients had only graduated from elementary school, so the level of education was low (Kim et al., 1970: 32).

In the 1963 outbreak, cholera was effectively contained, although it 
spread throughout the nation after the initial identification of cholera in the Pusan area. In 1964, El Tor Vibrio cholerae made another appearance in Inch'ŏn from September to November. Twenty people were infected and two died, but cholera was no longer a threat. It was not an epidemic. (Korea Centers for Disease Control and Prevention ed, 2002: 1).

At this time, medical schools, local governments, and the NID acquired popular knowledge of cholera and shared their information. Thus, despite the dualized central-local health prevention system, screenings and countermeasures in both the central and local governments were carried out organically and quickly. Moreover, cholera in the early 1960s was present mainly in the center of each province, where the central government maintained a significant influence. With fast reporting and enough medical resources, the cholera epidemic of 1963 revealed no cracks in the dualized health prevention system.

Up until the mid-1960s, cholera was still localized and could be contained. The disease was concentrated in large cities, so the epidemic reporting system was working well and the government was quick to deal with small-scale outbreaks. However, the quarantine policy established by the military government put distance between the central and provincial areas, and it could cause problems whenever infectious diseases occurred in provincial peripheries. Moreover, even during this period, the media coverage of cholera patients and deaths, government announcements, and academic positions varied (Lee and Park, 1966: 5051; Chŏn, 1965:4). 4) The government's death statistics were unreliable,

4) Unlike the government's announcement of the cholera fatality rate at 4.3\%, the media reported 7.7-9.2\%, while the medical community reported 6.6\%. "Settling the end of cholera quarantine (Chongŏnhan cholera pangyŏk ŭl kyŏlsanhae ponda),” Kyunghyang Shinmun, 21 October 1963; "Looking back of cholera (Cholera kyŏlsan)," Dong-A Ilbo, 
and there was a possibility that cholera could spread significantly if the discovery of cholera patients was delayed.

\section{Cholera Epidemic of 1969-70 and Politicization of the Anti- Cholera Administration}

1) Cholera Epidemic of 1969 and the Anti-Cholera Administration

The cholera pandemics in the late 1960s began in Udon Thani and Ubon Ratchathani in Thailand in June 1969. The disease spread to the Philippines, Vietnam, Singapore, and Hong Kong. In August 1969, the Korean government set up diarrhea centers in the three port cities of Pusan, Inch'ŏn, and Kunsan in preparation for the cholera outbreaks in Southeast Asia and launched a system to detect cholera patients early.

In the 1969 cholera epidemic, which began in August, problems of the dualized health prevention system of central and local were exposed as it led to a slow response to cholera quarantine and accelerated the spread of infection. On August 26, 1969, a 43-year-old man with diarrhea and vomiting was identified; he died two days later. Following his death, his neighbors began to die or show similar symptoms, and they were taken to the Kunsan Provincial Hospital. The local public health center was contacted through police office after four days on August 30, but at that time the center did not report the outbreak to the Ministry of Health and Social Affairs. On September 1, the Kunsan Quarantine Service detected one cholera case out of the five patients admitted. Only on September 2 did the Quarantine Service report the case of a cholera patient to the Ministry of Health and Social Affairs. That is, the central government

4 November 1963. 
was notified of the cholera epidemic one week after the outbreak. In the afternoon of September 2, the Ministry of Health and Social Affairs dispatched Lee Sŏng-woo, the chief of the Department of Disinfection, and Professor Kee Yong-suk of Seoul National University, to Okgu. In the morning of September 3, new cholera cases were reported on the west coast of Kunsan, Okgu, Sŏch'ŏn, and Koch'ang. According to these reports, 62 cholera cases occurred, of which 10 patients died. ${ }^{5)}$

On the same day, in a formal press conference, the government announced that the disease was not cholera but food poisoning. Using the result of the three rounds of feces tests as evidence, the government announced that this infectious disease was not cholera caused by El Tor Vibrio cholerae but food poisoning by Vibrio bacteria. Chŏng Hŭi-sŏp, the minister of Health and Social Affairs, also maintained that the disease was Vibrio food poisoning and lifted all anti-cholera measures. He added that he would do a final screening in Seoul to isolate the bacterium, since El Tor Vibrio cholerae and Vibrio bacteria belonged to the same lineage and required more thorough analyses. ${ }^{6}$

According to a booklet published by the Ministry of Health and Social Affairs, there had been no reports of deaths from Vibrio bacteria in 1969. However, as of September 3, 1969, the mysterious disease-be it cholera or food poisoning-recorded a mortality rate of $17.2 \%$ (Dong-A Ilbo reported 11 deaths among 64 cases), which was very similar to that of cholera El Tor, a disease known to have a 15\% mortality rate. Physicians at the Kunsan Provincial Hospital questioned the announcement of the

5) "Invasion of cholera into Kunsan, Okgu, Koch'ang, and Sŏch’ŏn [Kunsan, Okgu, Koch'ang, Sŏch'ŏn e cholera ch'imyip]”, Kyunghyang Shinmun, 3 September 1969.

6) "Turns out to be a food poisoning of Okgu cholera [Okgu cholera sikjungdok ŭro p'anmyŏng]", Dong-A Ilbo, 3 September 1969. 
Ministry of Health and Social Affairs, saying that the patients' symptoms were extremely similar to those of cholera, with "severe diarrhea and immobile paralysis." The physicians knew that Vibrio food poisoning would subside after 15 hours and patients would recover completely in two to three days, but their cases did not show this pattern. Even the Japanese government stated that the Korean government's announcement of Vibrio food poisoning was unreliable and that a Korean ship carrying allegedly cholera-infested Philippine timber to and from Kunsan would be quarantined for cholera. ${ }^{7}$

Once again on September 4, Minister Chŏng confirmed that this infectious disease was food poisoning. On September 5, Professor Kee Yong-suk, who participated in a field survey for the disease, said, "People should throw away the mindset that cholera is a terrifying disease and that if it is not [cholera], no disease can scare them." He stressed that food poisoning by Vibrio bacteria could also be terrifying. ${ }^{8}$ On September 6, the government decided that the pathogen was a "new Vibrio bacterium" as it was unable to confirm the presence of the Vibrio bacteria. Professor Kee Yong-suk argued that the bacterium's ecology was similar to that of Vibrio cholerae, which had a high infection and mortality rate, and therefore, as a precautionary measure, the new disease should be treated as if it had been cholera."

From September 4 to September 6, however, the NIH survey showed

7) "Strengthening quarantine of Korean ships [Han'guk paedŭng kŏmyŏk ŭl kanghwa]", Dong-A Ilbo, 4 September 1969.

8) "Dr. Kee's warning after the field investigation: Vibrio bacteria are also scary [Hyŏnji tanyŏ on Kee paksa ŭi Kyŏnggo]", Dong-A Ilbo, 5 September 1969.

9) "New Vibrio causes new cases to continue to increase [Shinjong Vibrio e much'aek shinhwan nŭlŏ ]”, Dong-A Ilbo, 6 September 1969. 
that antiserum tests concurrently yielded different results between food poisoning and cholera bacteria. The government dispatched Professors Kee Yong-suk, Chŏn Chong-hwi, and Kwŏn Yi-hyŏk to a local hospital on September 6 to conduct clinical tests to further clarify the NIH survey. After the result of 35 kinds of bacteriological tests was announced in the meeting room of the NIH on September 9, the minister of Health and Social Affairs and the professors proclaimed it could be a new type of cholera, different from cholera El Tor. ${ }^{10)}$

The first government announcement that the mysterious disease was Vibrio food poisoning was exacerbated by the second report that it might have been caused by a new type of Vibrio bacteria or a new strain of cholera; in the meantime, more cases continued to be filed. In addition to the government's poor response, another problem was that there had not been enough funds secured for quarantine. ${ }^{11)}$ It was not until September 9 that the usual cholera control measures could be employed. The Ministry of Health and Social Affairs ordered eight categories of emergency measures to be carried out in Ch'ungnam and Chŏnbuk Provinces, which were as follows. ${ }^{12)}$

(1) If patients are identified in two townships (Myŏn) or two villages (Tong), the Ministry of Health and Social Affairs will designate the region as an acute pollution zone.

10) "Conclusion of new type of cholera, food poisoning in Chŏnbuk province [Shinjong cholera ro tanjŏng, Chŏnbuk sikjungdok]”, Dong-A Ilbo, 9 September 1969; "There are 35 different bacterial tests, until the cholera alert came down [Segyun kŏmsamando 35kaji, cholera pisangyi naerigik'aji", Chosun Ilbo, 10 September 1969.

11) "Only 1.7 million wŏn for quarantine [Pangyŏkbi kyŏu 170 manwŏn]”, Dong-A Ilbo, 9 September 1969.

12) "Frightened locals and nervous quarantine agents again [Kŏp e chilin hyŏnji, tashi kinjanghan pangyŏkjin]”, Kyunghyang Shinmun, 9 September 1969. 
(2) Persons without cholera vaccination certificates should not enter the region.

(3) Fishing boats from disease-free areas should not enter the outbreak area.

(4) Fishing vessels from the contaminated area should not enter non-polluted areas.

(5) Measures to close schools in the polluted area will be decided by the governor and the superintendent of education.

(6) The export of fish and shellfish from the contaminated area should be suppressed.

(7) The sale of food that has not been heated for more than 10 minutes is prohibited in the contaminated area.

(8) Exterminate flies, the causative agents of cholera.

The most controversial of these measures concerned cholera vaccination and inspection. A vaccination certificate was required to pass through the contaminated area. If individuals did not have a certificate, they were forcibly inoculated. However, due to the lack of immunization drugs in the field, it was not possible to vaccinate them in time. The inspection team left quarantine stations after 5:30 p.m., and it was difficult to maximize the effectiveness of the quarantine. In addition, even after the government declared this epidemic to be a new type of cholera, its preventive measures continued to adopt a mixture of food poisoning and cholera policies. ${ }^{13)}$

In retrospect, it seems obvious that the epidemic was triggered by El Tor Vibrio cholerae; however, the fact that the government and some medical professionals had claimed it to be food poisoning or a new type of cholera created confusion in implementing the anti-cholera

13) "Current status and problems of local station of poor quarantine front [Ch'orahan pangyŏkjŏnsŏn hyŏnjisŏ pon silt’ae wa munjejŏm]”, Dong-A Ilbo, 11 September 1969. 
measures. On September 9, Chŏng Hŭi-sŏp, the minister of Health and Social Affairs, sought to resign for failure to prevent cholera. However, President Park Chŏng-hŭi refused to accept the minister's resignation and ordered him to do his best in the fight against the cholera epidemic. On September 12, the government formed a new cholera investigation group to identify the pathogen and trace the infection route again. On September 17, the first cholera death occurred in Seoul, and by then, the disease spread across the nation. On September 18, the opposition party called for the dismissal of the minister of Health and Social Affairs. During this initial period when confusion abounded, over 1,000 cholera cases occurred throughout the country in September alone. The uncertainty in government policy had claimed unnecessary victims. Cholera continued to spread in October, but as the weather got colder, the number of new patients began to dwindle; on November 4, the last case of cholera was confirmed in Kyŏngbuk province. In 1969, there were 1,538 cholera cases and 137 deaths (8.8\% mortality) nationwide.

\section{2) Cholera Controversy and Regression of the Health Administration}

In 1969, the chief director of the health administration was Chŏng Hŭi-sŏp (1920-87), who served as the 9th (1961.7.7-1963.12.31) and 12th (1966.4.15-1969.10.20) Minister of Health and Social Affairs. In other words, he had experienced two cholera epidemics during the six years he served as the minister. He was a graduate of Pyŏngyang Medical College (graduating in 1943) and played an important role in the military medical system as Surgeon General of the army troops after the Korean War. The resources available to Chŏng Hŭi-sŏp to strengthen the anti-pandemic administration were government agencies including 
the NIH, foreign aid organizations like the WHO and the US military, and medical professionals in prestigious medical schools. Among them, Chŏng Hŭi-sŏp most trusted the Seoul National University group, which had Professor Kee Yong-suk as its member. When the epidemic of 1969 occurred, three professors formed a sort of task force team: Professor Kee Yong-suk investigated the causative bacteria, Professor Chŏn Chonghwi from the Catholic Medical University conducted a clinical trial, and Professor Kwon Yee-hyŏk from Seoul National University performed an epidemiological investigation. ${ }^{14)}$ Professor Kee Yong-suk, in particular, was a pioneer in Korean microbiology and accumulated academic authority through extensive field experience and academic research following Japanese colonial rule. He was one of the leading scholars on cholera and plague. Thus, it was almost impossible for other medical professionals to refute his research or verify his research methodology.

The first presentation by Professor Kee Yong-suk was held on September 3. A team of government researchers, including Professor Kee himself, conducted a third round of testing for the cultivated strains from the patients, and they concluded that the strains were not Vibrio cholerae but Vibrio bacteria. ${ }^{15)}$ On September 4, Professor Kee Yongsuk stated that the detected Vibrio type was different from the cholera bacterium but it had similar toxicity and antigens; therefore, the current disease should be handled and treated as belonging to the category

14) "The Ministry of Health and Social Affairs' uncertainty, and as expected, cholera [Posabu kingaminga umulzumul kalp'angjilp'ang yŏksi cholera]", Dong- $A$ Ilbo, 10 September 1969.

15) "11 people died of food poisoning in four places [Negotsŏ sikjungdok 11myŏng samang]”, Dong-A Ilbo, 3 September 1969. 
of infectious disease like cholera El Tor. ${ }^{16)}$ On September 5, Professor Kee, after having participated in the field survey, stressed that Vibrio bacterial infection was as dangerous as cholera. ${ }^{17)}$ On September 6, the government authorities concluded that they were dealing with a "new Vibrio bacterium" because they could not confirm its identity in their tests. ${ }^{18)}$

It did not take much time for the cause of the infection to change from a new Vibrio bacterium to a new cholera strain. On September 8, 1969, having tested the samples from local patients in Kunsan, the NIH reported that cholera bacteria were found in its biochemical test results. The NIH said the announcements in 1963 and 1964 were based on biochemical test results while the test Professor Kee Yong-suk conducted in early September 1969 was a stool test that revealed a fungal cohesion establishment reaction and due to lack of proper instruments, his biochemical test failed to yield results. ${ }^{19)}$ Professor Kee did not seem to have accepted the NIH report.

On September 9, at a press conference announcing the new type of cholera, Professor Kee Yong-suk said that the initial test determined it to be triggered by enteritis Vibrio bacteria, but the retest by himself showed a reaction similar to that of Vibrio cholerae. Nevertheless, Professor Kee argued that the new cholera bacterium was tested negative on

16) "Similar cholera El Tor, we need to protect against contagion [El Tor hyŏng kwa pisŭt, chŏnyŏmsŏng pangyŏk haeyal”, Kyunghyang Shinmun, 4 September 1969.

17) "Dr. Kee's warning after the field investigation: Vibrio bacteria are also scary [Hyŏnji tanyŏ on Kee paksa ŭi Kyŏnggo]”, Dong-A Ilbo, 5 September 1969.

18) "New Vibrio causes new cases to continue to increase [Shinjong Vibrio e much'aek shinhwan nŭlŏ ]", Dong-A Ilbo, 6 September 1969.

19) "There is cholera reaction [Cholera panŭng natana]", Kyunghyang Shinmun, 8 September 1969. 
the polymyxin B test and hemolytic test, whereas the Classical biotype of Vibrio cholerae was found positive on the Voges-Proskauer test, indicating that the new cholera strain was different from the Classical biotype of Vibrio cholerae and the El Tor biotype of Vibrio cholerae. Professors Chŏn Chong-hwi and Kwŏn Yi-hyŏk attended the media conference. Professor Chŏn stressed that preventing dehydration was the only treatment because the new type of cholera manifested the same symptoms as those of common cholera, such as vomiting and diarrhea, although neither stomachache nor high fever was present. Professor Kwŏn explained that the fungus of the new strain was parasitic on fish and shellfish such as cockle, conch and clam, but it had not been directly transmitted from person to person. Based on the clinical symptoms and epidemiological investigation, both researchers supported the new cholera theory of Professor Kee Yong-suk in that the disease was not the same as cholera El Tor and showed a mixed pattern of food poisoning and cholera. ${ }^{20)}$

The media took a cynical stance toward the announcement of the new cholera theory. They thought, if the government persisted that the disease was quasi-cholera or food poisoning, the public would continue to be suspicious of its quarantine policy, and it was for this reason that the government intentionally declared the disease was a new type of cholera. They suggested that the preventive measures failed because of the monopoly of information by certain academic cliques, not to mention the government's unclear attitudes. With an exception of this specific

20) "What is the new type of cholera? Symptoms include abdominal pain and high fever [Shinjong choleraran muŏt yinga? Palbyŏng chŭngsenŭn poktong kwa koyŏl]”, Dong-A Ilbo, 9 September 1969. 
group of medical professionals, general researchers had no knowledge of the findings on the infectious disease or the results of the experiments. It was the media's viewpoint that the closed communication structure of the small medical professional group interfered with rational criticism or reasoning, leading to terrible results. ${ }^{21)}$

As health authorities turned to embracing the preventive measures for cholera, the interest of the medical community began to shift to finding out whether the causative bacteria were or were not new. The Japanese government was the first to show interest. Since the Korean government reported to the WHO that a new cholera strain was found on the west coast of the Korean peninsula, the Japanese government dispatched an investigation mission to Korea on September 15, 1969, to examine this finding. At that time, the Japanese government thought that the epidemic prevalent on the west coast of Korea was likely to be caused by El Tor Vibrio cholerae, and it strengthened the quarantine of ships coming from Korea. On September 19, 1969, Wataru Shitsukawa, the chief of the Inspection Team of the Japanese Ministry of Health and Welfare, announced that cholera in Korea was triggered not by a new type but by the El Tor Ogawa type. Due to the tight investigation schedule, Japanese investigators were unable to determine its transmission route. ${ }^{22}$

As early as November 1969, when the cholera outbreak was virtually concluded, a review of the cholera epidemic's infectious agents and transmission routes was conducted. On November 8-9 and November 29,

21) "Pitiful Korean bacteriology [Hansimhan Han'guk segyunhak]", Kyunghyang Shinmun, 13 September 1969.

22) "Japanese tests have revealed that Korean cholera is El Tor Ogawa type [Han'guk cholera nŭn El Tor Ogawa yil kŏmsa kyŏlgwa palkyŏjyŏl”, Kyunghyang Shinmun, 20 September 1969. 
the Korean Society for Microbiology and the Korean Society of Infectious Diseases, respectively, reviewed various issues related to cholera over the year. On December 23, the NIH held an international conference on cholera and went over various events during the cholera epidemic. Among them, the fungosity of Vibrio cholerae and its dormancy became major concerns. The two organizations agreed that its fungosity proved the bacterium to be El Tor Vibrio cholerae, but there was a disagreement over whether it was in a dormant state. Professor Kee Yong-suk noted that cholera in 1946 and 1963 remained dormant and re-emerged a few years later in 1969. Professor Lew Joon from Yonsei University argued that, while dormancy might be a subject of research, scientific data on the topic did not exist. ${ }^{23)}$

After 1969, Professor Kee Yong-suk received funding from the Ministry of Education three times for research on pathogenic Vibrio bacteria. Since Kee's research was socially controversial, all his research reports were considered confidential and not published externally. ${ }^{24)}$ In his 1970 report, Professor Kee did not agree that the 1969 cholera was caused by the El Tor biotype. He reported that not only the El Tor biotype and halophilic Vibrio but also a hybrid type of El Tor Ogawa and halophilic Vibrio had been isolated from the specimens of the patients (Kee, 1970). Since Professor Kee's alleged hybrid and mixed infections were rarely found in nature, this meant that the bacteria could have been intentionally

23) "Cholera conference [Cholera haksultaehoi]", Kyunghyang Shinmun, 24 December 1969.

24) Kee Yong-suk's 1970 and 1971 report were published in 1980 in the infection [Kamyŏm] journal of the Korean Society of Infectious Diseases, and the 1971 report was published in 1985 in the biography of Kee Yong-suk, along with microbiology [Misaengmulhak kwa tŏburŏ]. 
dispersed. On February 2, 1970, both Chŏn Chong-hwi and Kwŏn Yihyŏk supported this theory. However, Professor Lew Joon from Yonsei University and other medical professionals criticized Professor Kee Yongsuk's theory, with their own experiments that the infectious disease of 1969 and 1970 was indeed cholera (Hong, Lew, and Choi, 1971).

Professor Kee Yong-suk's theory provided a basis for an accusation that North Korea had dispersed cholera to South Korea. The media formally raised the possibility that North Korea might have smuggled cholera bacteria and embarked on bacteriological warfare. The Dong- $A$ Ilbo reported that cholera germs were found on the list of North Korean orders confiscated by the Japanese police in Kobe during an investigation into an electronic product smuggling case in 1969. Osaka Yanagida Co., Ltd. had smuggled 77 million won's worth of electronic parts, such as transistors, into North Korea 12 times between January 1969 and November $1969 .{ }^{25)}$ During the police seizure, a list of bacterial strain orders, including those for cholera, was found. In addition, North Korea had indeed been smuggling bacteria through Hong Kong. ${ }^{26)}$ Therefore, North Korea was accused of having smuggled and deliberately spread cholera in South Korea in 1969. Throughout February, the news of North Korea's bacterial trafficking was amplified through the media. In response, the Japanese Foreign Ministry stated that, while it was true that a Japanese company had received orders for bacterial strains from North Korea, it neither smuggled them out nor had anything to do with

25) "It was revealed during the cholera smuggling investigation that North Korea ordered germs from Japan [Choleradŭng milsususajung palkyŏjyŏ, pukgoi yilbon e palju]”, Dong-A Ilbo, 2 February 1970.

26) "North Korea's orders were relayed by Hong Kong corporation [Hong Kong sangsasŏ chunggye, pukgoi ŭi segyun paljul”, Kyunghyang Shinmun, 11 February 1970. 
the current El Tor Vibrio cholerae outbreak. Shizukawa, the head of the quarantine department in Japan, also judged that El Tor Vibrio cholerae was not suitable for use in bacteriological warfare because it was difficult to preserve and had a low fatality rate. ${ }^{27)}$

Kim T'ae-dong, who succeeded Chŏng as the minister of Health and Social Affairs, asked the WHO to investigate North Korea's alleged bacteria purchase. On February 19, 1970, Dr. Francisco J. Dy, deputy director of the WHO Western Pacific Region, and Dr. Yen, an investigator, arrived in Korea. The Japanese Ministry of Health and Welfare also dispatched an investigation team and started fact finding about the 1969 cholera outbreak in Korea. The WHO investigators' conclusion on the cholera epidemic was as follows (Chŏn Chong-hwi, 1975: 25):

First, there is a high possibility that cholera was introduced by the crew of foreign ships entering the port in Kunsan in August 1969. At that time, the isolated cholera strain was cholera El Tor Ogawa-type, and cholera of the same strain was spread in the Philippines.

Second, the possibility that the 1969 cholera was caused by chronic carriers or mild cases of cholera in 1964 cannot be ruled out.

Third, there is no convincing evidence that cholera in Korea in 1969 was caused by intentional spreading of germs.

In April 1970, the WHO officially notified the Korean government of these findings. In the 1969 outbreak, the cholera infection was most likely to have been brought about by a foreign craft and not been dispersed

27) "The whereabouts of cholera bacteria and whether to place orders in North Korea are unclear [Choleragyun ŭi haengbang, pukgoi palju sŏkyŏnch'anta]", Kyunghyang Shinmun, 14 February 1970. 
deliberately. ${ }^{28)}$ According to the NIH analysis, cholera had already been prevalent in the Celebes region of the Philippines, and from there, it flowed into Kunsan on six wooden carriers that traveled between the two regions between August 1 and 29, 1969. It was concluded that this way, cholera was transmitted into the port of Kunsan. ${ }^{29}$

In 1970, cholera emerged again in Pugok-myŏn, Ch'angnyŏng County, Kyŏngnam Province. On August 6, one day after returning from a nearby relative's house amidst the pouring rain, an old man died of unknown causes. About 70 local residents spent three days at his funeral, after which about 10 of them began to exhibit severe vomiting and diarrhea. On August 9, a public doctor reported these cases to the Ch'angnyŏng County public health center through a local health office and a branch office. Since the first patient case was identified in Ch'angnyŏng, the cholera epidemic had lasted for 86 days in the Ch'angnyŏng and Miryang Counties.

Unlike the Kunsan case in 1969, the head of the Ch'angnyŏng County public health center immediately reported the outbreak to the Ministry of Health and Social Affairs. However, the Ministry ignored the report, taking it to be another food poisoning case, and concluded that cholera could not have occurred in inland areas. As a result, the disease in Ch'angnyŏng County was placed under the Kyŏngnam Province government. As the disease continued to spread, the Ministry of Health and Social Affairs

28) "WHO informed the investigation team of the possibility of foreign ship infection [WHO chosadan t'ongbo oihangsŏn kamyŏm kanŭngsŏng]", Kyunghyang Shinmun, 13 April 1970.

29) "Concluding with a strain analysis notification that cholera broke into the Philippines last year [Chaknyŏn cholera pisŏ ch'myip, yingyunju punsŏkt'ongboro kyŏlon]”, Dong-A Ilbo, 19 August 1969. 
dispatched a bacterial inspection team directly and determined that it was El Tor Ogawa-type cholera. However, the Ministry, for some reason, announced that it was not cholera but pseudo-cholera, similar to food poisoning. Only when the NIH finally confirmed the cholera outbreak, the Ministry accepted this pronouncement. Eight days had passed since the first case of cholera. The number of patients had already increased to 73, with four deaths (Yang, 1970: 123-25). The preventive measures for cholera in Ch'angnyŏng County were not ideal, either; some patients managed to flee the isolation hospital at dawn without treatment or a meal, and the cholera infection soon reached nearby Miryang and Pusan. ${ }^{30)}$

On August 15, the Ministry of Health and Social Affairs made an official announcement that there was no Vibrio cholerae in Pusan. However, Professor Yang Hak-do from the Department of Microbiology at Pusan University reported the following: "As a result of culture test[s] for germs in Pusan city, 10 cases of El Tor Ogawa type were detected." He criticized the authorities' secrecy for exacerbating the cholera epidemic, even though the university hospital could determine, with a cholera test, whether it was authentic cholera or another disease within 20 hours and put down the infection. ${ }^{311}$

The belated efforts of health authorities could not reduce the number of cholera patients. On September 15, the Ministry of Health and Social

30) "Even Pusan in cholera [Cholera Pusan edo]", Kyunghyang Shinmun, 13 August 1970; "There is an escape disturbance at Ch'angnyŏng cholera camp [Ch'angnyŏng cholera hwanja suyongsosŏ t'alchul sodong]", Kyunghyang Shinmun, 17 August 1970.

31) "Dr. Yang at Pusan National University diagnosed 10 patients as genuine cholera patients [Pudae yangbaksa Pusan 10myŏng chinsŏng yida]", Dong-A Ilbo, 15 August 1970. 
Affairs announced 194 cholera patients and 10 deaths. ${ }^{32)}$ However, no new cases had occurred for 10 days since the last case on October 22 in Ch'angnyŏng, Kyŏngnam Province, and health authorities lifted the cholera-contaminated zone designation as of November 3 and notified the WHO of the related facts. According to the government's official announcement, there were 206 cholera cases and 12 deaths. ${ }^{33)}$

This time again, the media did not trust the claims made by health authorities. Contrary to the government's announcement, new cases continued to emerge and deaths were not uncommon in local communities; yet, the government denied that cholera had occurred. The media criticized the government for having separate statistics in drawers from those recorded on pin boards. ${ }^{34)}$ A classified presidential document I recently discovered lists 1,758 cholera patients and 60 deaths from the 1970 cholera outbreak (Presidential Secretariat, 1971). This shows that the number of patients was 5.8 times higher than what the authorities had admitted in their press announcements, and the number of deaths was more than five times higher, indicating that reporting had been thoroughly censored. In October 1969, the Park Chŏng-hŭi's Democratic Republican Party amended the Constitution to allow a third term for the president. However, the successive cholera epidemic in 1970 dealt a fatal blow to the legitimacy of the military regime. The

32) "Cholera is at a critical juncture [Cholera Kŭmmyŏngyi kobi]", Chosun Ilbo, 16 September 1970.

33) "Decontamination of cholera [Cholera oyŏm haeje]", Maeil Kyŏngje, 3 November 1970; "Decontamination of cholera area [Cholera oyŏm chigu haeje]", Kyunghyang Shinmun, 3 November 1970.

34) "When the cholera disaster occurred, the first report was inadvertently reported as food poisoning, and the government compiled double statistics [Cholera hwa, ch'ŏt pogoen sikjungdok yilteji pangsim, palbyŏng sanghwang e yijung t'onggye]", Chosun Ilbo, 26 December 1970. 
Park Chŏng-hŭi administration concealed facts in hopes of preserving economic benefits; it was not willing to increase uncertainty by offering facts and true diagnoses. Such secrecy over and concealment of the incidence of infectious diseases were rationalized as inevitable measures to counter economic losses in exports and tourism. ${ }^{35)}$ In fact, disclosing information on infectious diseases also became a controversial issue at the $78^{\text {th }}$ National Assembly's Health and Social Affairs Committee in 1971. Minister of Health and Social Affairs Lee Kyŏng-ho argued that, to support the national economy, there was a need to control press reports on important information regarding infectious diseases, such as cholera and encephalitis (National Assembly Secretariat, 1971).

\section{Conclusion}

In the 1960s, the military government established a health prevention system based on the Health Center Law (1962) and the IDPA (1963). The dualized health prevention system was operated by the central government with its emergency prevention, and the local government in charge of regular prevention. The system was entrusted with the "Revolutionary Tasks" of countering cholera, and its anti-cholera measures proved to be important in testing the power and will of the military regime. Since cholera was highly contagious and had a high mortality rate, precise strategies and tactics were needed in preparation for the "cholera prevention war."

Chŏng Hŭi-sŏp, the minister of Health and Social Affairs, who had

35) "Eighty six days of cholera in agony [Shi shi komin sok ŭi cholera 86 yil]", Kyunghyang Shinmun, 4 November 1970. 
gained the trust of Park Chŏng-hŭi as Surgeon General, tried to actively cope with the spread of cholera by drawing up a manual of preventive measures against the disease in 1963. In the early days of the cholera epidemic in 1963, cholera originated in Pusan and expanded nationwide, but it was detected relatively early and could be contained. Despite the dualized health prevention system of central and local, the cholera disinfection measures developed rapidly and organically at both central and local levels. In other words, it was difficult to identify cracks in the dualized health prevention system, as cholera was localized in the center of each province until the mid-1960s.

In contrast to the 1963 and 1964 epidemic, the cholera epidemic of 1969 exposed several problems of the dualized health system. The first concerned the epidemic reporting system. The central public health administration was directed by the Ministry of Health and Social Affairs, whereas local public health was under the auspices of the Provincial Health Bureau and its subordinate public health centers. These public health centers were operated using local tax revenues, and the public health centers, whose personnel was appointed by each provincial governor, did not report directly to the central government. In 1969, when the first cholera case of the year occurred in Kunsan, the central government was not informed. It belatedly learned of the cholera epidemic only because the Kunsan Quarantine Service, an agency directly affiliated with the Ministry of Health and Social Affairs, reported the related facts. In the end, the central government could not know the exact situation until the agency under its jurisdiction made a report. Ambiguities in the reporting structure of the central and local governments and in the division of roles prevented the public health system from functioning organically. 
Second, the central government was heavily dependent on a specific group of medical professionals. The government relied on this group of medical experts rather than on state-run research institutions such as the $\mathrm{NIH}$ and the NID. As a result, the decision to quarantine was made in a closed and dogmatic environment with only a small number of medical professionals monopolizing information and resources. It is hard to say that Kee Yong-suk and his group intentionally distorted or manipulated the research results to suit the taste of the military government, but it is clear that there was little opportunity for other researchers to review their research and its methodological problems. However, the spread of cholera throughout the country no longer allowed a specific group to monopolize the information they needed. Numerous medical school laboratories began to conduct research and analysis of their own, and the newly shared knowledge inevitably fueled controversy. Furthermore, as external quarantine agencies such as the U.S. military, Japan's Ministry of Health and Welfare, and the WHO conducted independent investigations and publicized their opinions, monopolizing information by a certain group of medical professionals became untenable.

Third, the media and medical professionals critical of the government and suspicious of its motives, gained more voices to expose problems with the quarantine measures. Under the pretext of economic reconstruction, the military government pushed for industrialization centered on large corporations, suppressed the human rights of workers and antigovernment figures, and revised the Constitution to allow long-term rule. To divert the public attention, the government also politicized quarantine; it highlighted North Korea's intention in bacteriological warfare and strengthened the secrecy of the quarantine administration. Nevertheless, 
some media outlets and medical professionals, who did not belong to the select group of medical experts under the government's wing, did challenge the government's politicization of secrecy and quarantine and could earn a modicum of respectability. Still, the government succeeded in either concealing or classifying its reports on the cholera epidemic in 1969 and 1970. Instead of reforming the health system to carry out the Revolutionary Tasks in the "cholera prevention war," the military government took the path of reducing and concealing the infectious disease information to ease its political burden.

Keywords: Cholera Epidemic, Park Chŏng-hŭi's Military Government, Medical Professional Groups, the Politicization of Preventive Administration, Bacteriological Warfare, Korea 
SIHN Kyu-hwan : Concealment and Disclosure: The Cholera Crisis of 1969-70 in Korea

\section{REFERENCE}

$\langle$ Primary Sources $>$

Chosun Ilbo (Korea Daily)

Dong-a Ilbo (Dong-a Daily)

Kamyŏm (Infection)

Kukmin Ilbo (National Daily)

Kwanbo (Official Gazzette)

Kyunghyang Shinmun (Kyunghyang Newspaper)

Maeil Kyŏngje (Daily Economics)

Choi, C. C., Public Health in Korea (Deputy Minister of Public Health and Welfare, American Military Government, Seoul, Korea. 1949).

Kee, Yong-suk, Yŏn-t'ae Lee and Chong-hun Lee, "A Study on the Pathogenic Vibrio Fungus in Korea's Natural Environment [Han'guk chayŏnhwangyŏng nae e punpodoin byŏngwŏnsŏng vibrio kyunsok e kwanhan chosa]," The Report of the Ministry of Culture and Education (Mungyobu Bogosŏ) (1970), pp. 1-16, reprinted in Infection [Kamyŏm] 12-1 (1980).

Kim, Don-kyoun, Joon-yun Kim and Young-tae Suh, "An Epidemiological Survey on Cholera in Pusan City 1970," Korean Journal of Preventive Medicine 3-1 (1970), pp. 31-36.

Korean Government-General [Chosen Sotokufu], The 1919 Report on Cholera Prevention Activities [Taisho Hachinen Korerabyo Boekishi] (Keijo[Seoul]: Korean Government-General, 1920) [朝鮮總督府, 『大正8年虎列刺病防疫誌』(京 城: 朝鮮總督府)].

Korean Government-General [Chosen Sotokufu], The 1920 Report on Cholera Prevention Activities [Taisho Kyunen Korerabyo Boekishi] (Keijo[Seoul]: Korean Government-General, 1921） [朝鮮總督府,『大正9年コレラ病虎防疫誌』 (京城: 朝鮮總督府)].

Hong, Chung-pyo, Joon Lew, and T'ae-kyŏng Choi, "The Vibrio Cholerae Isolated During Cholera Epidemics in Korea in 1969 and 1970," Yonsei Medical Journal 12-1 (1971), pp. 42-48.

Lee, Chong-sŭng and Kee-dŏk Park, "Bacterial Investigation Project: Report on Cholera 
Prevention in 1963 [Segyun Chosa saŏp: 1963nyŏndo Cholera Pangyŏkbogo]," The Report of National Institute of Health [Kuklip Pogŏnwŏnbo] 3 (1966), pp. 44-52.

Presidential Secretariat, Comprehensive Report on Cholera Prevention in 1971 [71nyŏndo cholera pangyŏk chonghapbogo], (Seoul: Presidential Secretariat, 1971).

The Committee on Health and Social Affairs in the Korean National Assembly, The $73^{\text {rd }}$ Fifth Committee Proceedings on Health and Social Affairs in the Korean National Assembly [Che73hoi che5cha pogŏnsahoi uiwŏnhoi hoiŭirok], 18 June 1970.

The Ministry of Health and Social Affairs, Cholera Emergency Preventive Measure [Cholera kingŭp pangyŏk taechaek], Seoul: The Ministry of Health and Social Affairs, 20 August 1962.

The Ministry of Health and Social Affairs, Cholera Guideline for Preventive Measure [Cholera pangyŏk taechaek yoryŏng], Seoul: The Ministry of Health and Social Affairs, 21 September 1963a.

The Ministry of Health and Social Affairs, Strengthening Cholera Preventive Measure [Cholera pangyŏk taechaek ŭi kanghwa], Seoul: The Ministry of Health and Social Affairs, 24 September 1963b.

The Ministry of Health and Social Affairs, Status Report for Cholera Preventive Measure [Cholera pangyeŏk taechaek hyŏnhwangbogo], Seoul: The Ministry of Health and Social Affairs, 30 September 1963c.

The Ministry of Health and Social Affairs, Performance and Prospect of Health and Social Administration [Pogŏnsahoi haengjŏng ŭi siljŏk kwa chŏnmang], Seoul: The Ministry of Health and Social Affairs (1971).

Yang, T'ae-sik, "Retrospect and Prospect of Preventive Measures [Pangyŏk taechaek ŭi hoigo wa chŏnmang]," Local Administration [Chibanghaengjŏng] 19-12 (1970), pp. 120-125.

\section{〈Seconary Sources >}

Chŏn, Chong-hwi, Acute Infectious Disease in Korea [Han'guk Kŭpsŏng chŏnyŏmbyŏng kaegwan]. (Seoul: Ǔiyakgyŏsa, 1965).

Chŏn, Chong-hwi. Acute Infectious Disease in Korea [Han'guk Kŭpsŏng 
SIHN Kyu-hwan : Concealment and Disclosure: The Cholera Crisis of 1969-70 in Korea

chŏnyŏmbyŏng kaegwan]. (Seoul: Ch'oishin ŭihaksa, 1975).

Ch’ŏn Pyŏng-ch'ŏl and Jin-hyŏk Kim, “The Korean Government's Prevention Activities and Assessment of Cholera in 1969 [1969nyŏn han'guk chŏngbu ŭi cholera pangyŏk hwaldong kwa pyŏngga]," Conference Proceedings of the Korean Society for the History of Medicine, Oct. 2015.

Korea Centers for Disease Control and Prevention, Guidelines for Cholera Control [Cholera Pangyŏk kwalli chich'im], (Korea Centers for Disease Control and Prevention, 2002).

Kee Yong-suk Memorial Collection Publishing Committee [Kee Yong-suk Ch'umojip palgan uiwŏnhoi], Along with Microbiology [Misaengmulhak kwa dŏburŏ] (Kee Yong-suk Memorial Collection Publishing Committee, 1985).

Kim, Tong-han, "The Shape of Vibrio Cholerae separated in Korea [Han'guk esŏ pulidoin cholera kyun ŭi hyŏngsang]," M.A. Thesis., Ehwa Women's University, 1972.

Kim, Chŏng-sun, "The Historical Research of Cholera Epidemic in Korea [Urinara cholera yuhaeng ŭi yŏksajŏk kochal]," The Health Complex Conference in 1991 [1991nyŏn Pogŏnhaksul taehoi] (1991), pp. 70-83.

Kim, Sŭng-hŭi, "Medical Political Science Review of Cholera Occurred in the 1969-70 Korea [1969-1970nyŏn Han'guk esŏ palsaenghan cholera e taehan ŭiryosahoihakjŏk kochall," Ph. D. Thesis, Korea University, 2014.

Kim, Sŭng-hŭi. "The Power Life and Its Limits in 1969 through Cholera in Korea [1969nyŏn han'guk esŏ palsaenghan cholera rŭl t'onghaesŏ pon saengmyŏng kwŏllyŏk kwa kŭ hangyŏ]," Journal of Social Thought and Culture [Sahoisasang kwa Munhwa] 18-1 (2015), pp. 217-248.

Lee, Kyu-sik. "Kee Yong-suk's Research and Life: Focusing on Cholera Research [Kee Yong-suk ŭi yŏngu wa saengae: cholera yŏngu rŭl chungsim ŭro]," Korean Journal of Medical History 16-1 (2007), pp. 71-81.

Lim, Hyeon-sul, "The Epidemic Properties and Causes of Cholera in Korea [Han'guk esŏ palsaenghan cholera ŭi yŏkhakjŏk t'ŭksŏng mit palsaeng wŏnyin]," Tongguk Medicine [Tongguk ŭihak] 9-2 (2002), pp. 1-24.

KSID (The Korean Society of Infectious Diseases), History of Infectious Diseases in Korea [Han'guk chŏnyŏmbyeŏngsa] 2 (Seoul: Kunja Publishing Press, 2018). Abstract 


\title{
Concealment and Disclosure: The Cholera Crisis of 1969-70 in Korea ${ }^{\dagger}$
}

\author{
SIHN Kyu-hwan*
}

The anti-cholera measures of 1969-70 represent one of the most unsuccessful quarantine cases in modern Korea. The military government, which overthrew the democratic government in 1961, tried to amend the Constitution aiming for a long-term seizure of power, and had to overcome the cholera crisis of 1969-70. Previous scholarship has emphasized the limitation of the state power when it came to controlling the cholera epidemic or the poor sanitation system of 1969-70. However, it is undeniable that the military government did have organizations, facilities, and human capital available. When a cholera epidemic broke out in 1963-64, the military government defended its people against cholera as part of the Revolutionary Tasks. Furthermore, it took counsel from a team of medical professionals knowledgeable in microbiology. In 1969, the possibility of bacteriological warfare by North Korea emerged while the government responded to cholera. To avoid this crisis, Park

\footnotetext{
†This research was supported by Daegu University Research Grant, 2020.

*Assistant Professor, Dept. of History Education, Daegu University, Chinese History and East Asian History of Medicine major / E-mail: jerry0406@daegu.ac.kr
}

Received: Jul. 01, 2021; Reviewed: Jul. 29, 2021; Accepted: Aug. 12, 2021 
Chŏng-hŭi's military government, which had been preparing for longterm rule, had to provide successful model in the cholera defense. For the military government, the concealment and distortion of infectious disease information was inevitable. Many other medical professionals trusted the activities of international organizations more than they did the government bodies, and the media accused the government of fabricating cholera death statistics. As the government failed to prevent the cholera crisis, it tightened its secrecy by concealing facts and controlling information.

Keywords: Cholera Epidemic, Park Chŏng-hŭi's Military Government, Medical Professional Groups, the Politicization of Preventive Administration, Bacteriological Warfare, Korea 